Ege Eğitim Dergisi 2014 (15) 1: 318-337

\title{
Gerçek Yaşam Durum Senaryolarıyla Bilişim Etiği Ölçeği’ni Türkçeye Uyarlama Çalışması*
}

\author{
Y. Deniz ARIKAN ${ }^{* *}$ Saliha Handan DUYMAZ ${ }^{* * *}$
}

\begin{abstract}
Öz
Literatürde bilişim teknolojilerinin etik kullanımına ilişkin yapılan çalışmalarda senaryo tabanlı ölçeklerin yaygın olarak kullanıldığı görülmektedir. Ülkemizde bu tür ölçeklerin kullanımının sınırlı olması nedeniyle, bu çalışmada, Yoon (2011) tarafından geliştirilen Gerçek Yaşam Durum Senaryolarıyla Bilişim Etiği (GYDSBE) Ölçeği'nin Türkçeye uyarlanması amaçlanmıştır. GYDSBE Ölçeği bilişim teknolojilerinin kullanımında karşılaşılan sorunlara ve ahlak felsefelerine dayanmaktadır. Orijinali İngilizce olan ölçek, 17 maddeden oluşmakta ve yedi dereceli Likert tipi bir ölçektir. GYDSBE Ölçeği'ni Türkçeye uyarlama sürecinde dil ve alan uzmanlarının görüşleri alınmıştır. Geribildirimler doğrultusunda ön deneme uygulaması yapılmıştır. GYDSBE Ölçeği'nin dil geçerliği çalışması (n=87), geçerlik ve güvenirlik çalışmaları $(n=362)$ için ayrı uygulamalar yapılmıştır. Dil geçerliği çalışması sonucunda GYDSBE Ölçeği'nin İngilizce formu ile Türkçe formunda yer alan senaryolar arasında anlamlı ilişki bulunmuştur $(p<.00)$. Geçerlik için yapılan açımlayıcı faktör analizi sonucunda maddelerin tamamının birinci boyutta yüksek faktör yüküne sahip olduğu bulunmuştur. GYDSBE Ölçeği'nin tüm senaryoları ayırt edici $(p<.00)$ ve iç tutarlık katsayısı yüksek bulunmuştur. Yapılan bu çalışmanın sonucunda GYDSBE Ölçeği'nin Türkçe formunun geçerli ve güvenilir olduğu belirlenmiştir.
\end{abstract}

Anahtar kelimeler: Bilişim etiği, bilişim etiği ölçeği, senaryo tabanlı ölçek

Ege Eğitim Dergisi 2014 (15) 1: 318-337

* Bu çalışma Y. Deniz ARIKAN danışmanlığında Saliha Handan DUYMAZ tarafindan yapılan “Ortaokul Öğrencilerine Yönelik Bilişim Etiği Öğretim Programı Uygulaması" başlıklı tez çalışmasının bir bölümünün özetidir.

** Yrd. Doç. Dr., Ege Üniversitesi Eğitim Fakültesi, y.deniz.arikan@ gmail.com

*** Öğretmen, Milli Eğitim Bakanlı̆̆ı, handanduymaz@ hotmail.com 


\title{
The Adaptation Study of Real Life Situation Scenario Information Technologies Scale to Turkish
}

\begin{abstract}
Ethical use of information technologies studies in the literature has been used widely in scenario-based scales. Because of limited usage of such scales in Turkey, Real-Life Situation Scenarios Information Technologies Ethics (RLSSITE) Scale, which was developed by Yoon (2011), was adopted in Turkish in this study. RLSSITE Scale is based on moral philosophy and the problems encountered in the use of information technologies. The original version of RLSSITE Scale is English, and the seven-point Likert-type. RLSSITE Scale consists of 17 items. The views of language and IT specialists got during the adaptation of the RLSSITE Scale in Turkish process. Pre-test was conducted in line with the feedback. Linguistic validity study $(n=87)$, and the structural validity and reliability studies $(n=362)$ were made. It was found a significant correlation $(p<.00)$ between the English version of the RLSSITE Scale and the Turkish version of the scale. According to the principal component analysis, it was determined that the factor loads of all items were high in the first dimension. It was also found that all of the scenarios were discriminated and revealed an internal consistency for all scenarios was high. As a result of this study, it was determined that RLSSITE Scale can be accepted as a valid and reliable tool which can be used in Turkish.
\end{abstract}

Keywords: IT ethic, IT ethic scale, scenario based scale 



\section{Giriş}

Bilişim etiği, bilişim teknolojileri araçlarını kullanırken uyulması gereken kuralları tanımlayan normlar olarak tanımlanmaktadır. Bu normların temel amacı kullanıcıların minimum zarar ve maksimum fayda ile elektronik ortamı kullanmasını güvence altına almaktır (Sevindik, 2011). Bilişim etiği, bilişim alanında hizmet sunanların ve alanların davranışlarını inceleyen bir felsefe dalı olup; etiğin uygulamalı bir alt alanıdır (Türkiye Bilişim Derneği, 2010). Bilişim etiği kavramı ilk başlarda bilgisayar etiği olarak ortaya çıkmış, internetin yaygınlaşması ile birlikte internet etiği kavramını da kapsar hale gelmiştir.

Wiener, 1950'de yayınladığ 1 The Human Use of Human Beings adlı kitap nedeniyle bilgisayar etiğinin kurucusu olarak görülmektedir. Araştırmacılar 1980'lerin başında bilgisayar etiğini yeni bir uygulamalı etik sahası olarak görmeye başlamışlardır (Bynum, 2000). Bynum, 1978'de bilgisayar etiği için bir ders programı hazırlamış ve üniversitede bu konuda dersler vermiştir. 1985'te Metaphilosophy dergisinin özel konusu "Bilgisayar ve Etik" olmuştur (Moor, 1985). İletişim Teknolojilerinin yaygınlaşması ile birlikte bilişim etiği, sık sık sözü edilen bir kavram haline gelmiştir (Örs, 2010). Türkiye Bilişim Derneği'ne (2010) göre, bilişim etiği kapsamında bilgisayar kullanımına, internet kullanımına, bilişim sistem ve ağ yönetimine, yazılım geliştirmeye, adli ve yönetsel incelemelere ve son kullanıcıya yönelik etik kurallar yer alır. Bu kuralların şekillenmesinde bilişim teknolojileri ile ortaya çıan etik sorunların belirleyici olduğu görülmektedir (Mason,1986; Johnson, 2000; Dedeoğlu, 2001).

Bilişim teknolojilerinin etik kullanımını betimlemeye yönelik araştırmalarda, cinsiyet, yaş, aile eğitim durumu, aile gelir durumu gibi demografik özelliklere göre incelemeler yapıldığı görülmektedir. Bu araştırmaların bir kısmında bilişim teknolojilerinin etik kullanımına ilişkin tutumları ölçmede senaryo tabanlı ölçeklerden yararlanıldığı görülmüştür (Loch ve Conger, 1996; Adam ve Ofori-Amanfo, 2000; Dorantes, Hewitt ve Goles, 2006; Masrom, Ismail, Anuar, Hussein ve Mohamed 2010; Yoon, 2011).

Loch ve Conger (1996) on senaryo hazırlayarak, kullanıciların bilgisayar kullanırken karşılaştıkları gizlilik, kaynak mülkiyeti gibi durumlarda sergiledikleri tutum ve davranışları incelemişlerdir. Çalışma New York, Texas ve Georgia'daki dört kent üniversitesinde, 174 katılımcı ile gerçekleştirmiştir. Araştırmacılar, bilgisayar kullanımında etik karar verme süreçlerini; tutum, sosyal normlar, bilgisayar okur-yazarlığı ve yaş, meslek, sosyo-ekonomik 
Gerçek Yaşam Durum Senaryolarıyla Biliş̧im Etiği Ölçeği'ni Türkçeye Uyarlama Çalışması 321 durum gibi kişisel özelliklere göre incelemiştir. Araştırmada faktör analizi sonucunda teknik uygulama dokümanlarının alınması, iş yerinde arkadaşınız için program çalıştırma, başkalarının e-postalarını okuma olmak üzere üç senaryodan yararlanmişlardir.

Bir başka çalışmada, Adam ve Ofori-Amanfo (2000) Bilgi ve İletişim Teknolojileri kullanımını çevreleyen etik konuları cinsiyet farklılığı açısından incelemek amacıyla, bilgisayarın etik kullanımıyla ilgili problemler içeren senaryolar oluşturmuşlardır. Senaryolar; kopya yazılımlar, korsanlık, e-posta yoluyla taciz gibi bilgisayar etiği ile ilgili problemlerden, ikilemlere neden olan durumlardan oluşmaktadır. Araştırma sonucunda, daha fazla belirsiz durumlar içeren senaryolar geliştirilmesi gerektiği vurgulanmıştır.

Dorantes, Hewitt ve Goles (2006) etik senaryolar kullanarak bilgi teknolojileri kullanımında etik karar verme süreçlerinde, kişisel ahlak felsefesinin ve ahlak yoğunluğunun rolünü incelemişlerdir. Çalışma Amerika Birleşik Devletleri'nde işletme eğitimi alan, bilgi sistemleri dersine kayıtlı 318 öğrenci ile yürütülmüştür. Araştırmada bilgi teknolojilerini kullanırken etik karar verme süreçlerinde kişisel ahlak felsefelerinin ve dini inançların ve cinsiyetin etkili olduğu belirlenmiştir.

Masrom, Ismail, Anuar, Hussein ve Mohamed (2010) bilgi teknolojileri alanındaki etik konulara ilişkin algıları belirlemek amacıyla sekiz senaryodan yararlanarak bir araştırma gerçekleştirmiştir. Çalışma, Malezya Teknoloji Üniversitesi Uluslararası Kampüsü'nde, bilgisayar bilimleri alanında, lisans öğrenimi gören 100 öğrencinin katılımıyla yapılmıştır. Bu çalışmada kullanılan senaryoların veri doğruluğu, fikri mülkiyet, erişilebilirlik ve gizlilik konularıyla ilgili olarak yapılandırıldığı görülmektedir.

Yoon (2011), internet ortaminda etik karar vermeyi ahlak teorilerine dayandıran bir model önermiş ve bu modeli deneysel olarak test etmek için internet üzerinde etik ikilemler yaratan gerçek yaşam durumları içeren dört senaryodan yararlanmıştır. Çalışma 111 üniversite öğrencisi ile gerçekleştirilmiştir. İnternet üzerinde etik ikilemler sunan senaryolar mahremiyet, ifade özgürlüğü, fikri mülkiyet ve doğruluk ile ilgilidir.

Yoon'un senaryolarında ele aldığı sorunlar günümüzde oldukça önemlidir. Bilgi çă̆ının temel sorunlarından birisi mahremiyettir. Mahremiyet, bilişim 
ortamlarında kişisel bilgilerin gizliliği ve korunması ile ilgilidir. Lesk (2005) bu noktada, a)kişisel bilgilerin tutulacağı yerin b)toplanan bilgilerin kişiyi tanımaya yönelik olup olmadığının, c)kayıtların tutulacağı sürenin d)bu bilgilere kimlerin erişebileceğinin önemli olduğunu belirtmiştir. İfade özgürlüğü ise, alanyazında ifade hürriyeti, düşünce hürriyeti, düşün hürriyeti, düşünme hürriyeti, düşünceyi açıklama özgürlügüu, fikir açıklama özgürlüğü, konuşma özgürlüğü, iletişim özgürlüğü olarak da kullanılmaktadır. Fikri mülkiyet, bir kişinin düşüncesiyle ürettiği ürünün mülkiyetidir. Bu ürünler bir buluş, bir müzik notası, bir kitap, ressamın çizdiği tablo, bir şiir veya bir bilgisayar yazılımı olabilir. Telif hakkı ise fikri mülkiyeti koruyan haklardan oluşur. Edebi veya bilgisayar yazılımı dahil sanatsal eserlerin sahiplerine sağlanan hakları ifade eden bir hukuki terimdir (Türk Patent Enstitüsü, 2012). İnternetin sağladığı sosyal potansiyel, hangi bilgilerin doğru ve güvenilir olduğu konusunda belirsizliklere neden olmaktadır. Floridi'ye (1995) göre, internet herkesin istediği bilgiyi yükleyebileceği bir alan olduğu için entelektüel çöplüğe dönüşme potansiyeline sahiptir. Bu nedenle internet doğru bilgi gibi, doğru olmayan bilginin de yayılmasını kolaylaştırabilmektedir (Johnson, 2000). Bilişim etiği kavramı kapsamında bu sorunlarla birlikte sayısal uçurum ve siber zorbalık gibi sorunlarda yer almaktadır. Sayısal uçurum (digital divide) farklı sosyoekonomik düzeydeki bireylerin, firmaların veya ülkelerin bilgi iletişim teknolojilerine erişiminde ve kullanımında yaşadığı eşitsizlik olarak tanımlanmaktadır (OECD, 2011). Siber zorbalık ise, web siteleri, anlık mesajlaşma, bloglar, sohbet odaları, cep telefonları, elektronik posta gibi elektronik araçlar vasitasıyla diğer bireylerin tehdit edilmesi, küçük düşürülmesi veya onlara cinsel objeler içeren resim ve mesajların gönderilmesidir (Shariff, 2005).

Bilgi ve iletişim teknolojileri gibi dinamik ve karmaşık bir alan için etik kuralların varlığı bireylere etik davranış ve bilinç kazandırmak için tek başına yeterli değildir. Biliş̧im teknolojilerindeki etik dışı davranışların en aza indirmek öncelikle bilişim etiği konusunda farkındalık yaratmak, etik bir anlayışın geliştirilmesini sağlamakla mümkün olabilir. Bu farkındalık ve anlayışın küçük yaşlarda sağlanması önem taşımaktadır. Bilişim teknolojilerinin günlük yaşamda kullanımı ile artan bu sorunlar nedeniyle etik eğitiminin otantik ortamlarda gerçek olgulara dayalı, sürekli, bütüncül ve sade olarak eğiticiler tarafından verilmesi önemli görülmektedir (Siegler, 2002).

$\mathrm{Bu}$ amaçla bilişim teknolojilerinin etik kullanımına yönelik çalışmalarda çeşitli belirsizlikler, ikilemler sunan senaryo tabanlı ölçeklerden yararlanılmaktadır. Ülkemizde bu tür senaryo çalışmaların sınırlı olduğu görülmektedir. Bu 
Gerçek Yaşam Durum Senaryolarıly Bilişim Etiği Ölçeği'ni Türkçeye Uyarlama Çalışması 323 araştırmada ülkemizde gerçekleştirilecek bilişim etiği öğretimi uygulamalarına katkı sağlaması amacıyla, bilişim etiğinde güncel ve önemli sorunları ele aldığ1 düşünülen, Yoon (2011) tarafından geliştirilen GYDSBE Ölçeğinin Türkçe'ye uyarlanması amaçlanmıştır.

\section{Yöntem}

\section{Gerçek yaşam durum senaryolarıyla bilişim etiği ölçeği}

GYDSBE Ölçeği'nin orijinali, internet üzerinde etik ikilemler yaratan gerçek yaşam durumları içeren senaryolar ve bu senaryolara göre cevaplanacak 16 maddeden oluşan, 7 dereceli Likert tipi bir ölçektir. Ölçekte, katılımcıların senaryolarda verilen bir örnek olay hakkında verilen maddelere katılma durumlarını belirtmeleri beklenmektedir. Senaryolarda yer verilen olaylar günlük yaşamdan seçilen gerçekçi olaylardır. GYDSBE Ölçeği adalet, görecelik, egoizm, görev bilgisi ve faydacılık olmak üzere beş ahlak felsefesi değişkeni temel alınarak oluşturulmuştur. GYDSBE Ölçeği'nde adalet ilkesi için iki madde, görecelik ilkesi için üç madde, egoizm ilkesi için iki madde, görev bilgisi ilkesi için dört madde, faydacıllk ilkesi için üç madde ve etik davranışsal niyetlerin etkisini belirlemek için iki madde yer almaktadır. Maddeler kesinlikle katılmıyorum-kesinlikle katıllyorum arasında yedi dereceli Likert tipi ölçek biçiminde düzenlenmiştir. Ölçekten alınan yüksek puanlar, bilişim teknolojilerinin etik kullanım düzeyinin yüksek olduğu, düşük puanlar ise bilişim teknolojilerinin etik kullanım düzeyinin düşük olduğu anlamına gelmektedir. GYDSBE Ölçeği'nin güvenirlik ve geçerlik çalışması Güney Kore'deki bir üniversitede 66 erkek ve 45 kadın olmak üzere toplam 111 öğrencinin katılımıyla yapılmıştır. GYDSBE Ölçeği senaryolarının en düşük 0.722, en yüksek 0.968 düzeyinde iç tutarlığa sahip olduğu belirtilmiştir.

\section{GYDSBE Ölçeği uyarlama süreci}

GYDSBE Ölçeği'nin Türkçeye uyarlama çalışmalarının ilk aşamasında, İngilizce, Türkçe ve bilişim teknolojileri alan uzmanlarının görüşleri alınmıştır. Uzman görüşleri doğrultusunda düzenlenen ölçeğin ön deneme uygulaması yapılmıştır. Ön deneme uygulaması geribildirimleri doğrultusunda ölçeğe son şekli verilerek, 87 ortaokul öğrencisinin katılımı ile dil geçerliği çalışması yapılmıştır. Uyarlama sürecinin son aşamasında ölçek 362 ortaokul öğrencisine uygulanmış ve elde edilen veriler ile geçerlik ve güvenirlik çalışması yapılmıştır. Ölçek kapsamında senaryolarda ele alınan mahremiyet, ifade 
özgürlüğü, fikri mülkiyet ve doğruluk gibi bilişim etiği sorunların, bilişim teknolojilerinin günlük yaşamda ve eğitimin her kademesinde kullanımının yaygınlaşması sebebiyle, üniversite öğrencileri kadar ilkokul, ortaokul ve lise öğrencilerinin de yaşadığı bilinen bir olgudur. Bununla birlikte, 2006 yılında Milli Eğitim Bakanlığı tarafından yayınlanan İlköğretim Bilgisayar Dersi (1-8. sınıflar) Öğretim Programı'nda, bilişim teknolojileri etiği ve sosyal değerler başlıklı bir öğrenme alanına ilişkin kazanımlar ile içerikler yer almaktadır. Bu nedenlerle ölçeğin uyarlama sürecine orta okul öğrencileri katılmıştır.

\section{Bulgular}

\section{Dil geçerliği}

GYDSBE Ölçeği'nin orijinali bir üniversitede görev yapan beş İngilizce okutmanı tarafından Türkçeye çevrilmiş ve daha sonra Türkçe formlar aynı uzmanlar tarafından İngilizceye çevrilerek iki form arasındaki tutarlık incelenmiştir. Uzmanlar Türkçe formlar üzerinde tartışarak anlam ve dilbilgisi açısından gerekli düzeltmeleri yapmış ve denemelik Türkçe form elde edilmiştir. Denemelik Türkçe form bilişim ve etik konularında uzman üç öğretim görevlisi ve dört bilişim teknolojileri öğretmeni tarafından incelenmiş ve gelen görüşler doğrultusunda son değişiklikler yapılarak ölçek beş dereceli Likert tipi olarak düzenlenmiştir. Türkçe form ilk olarak 15 altıncı sınıf öğrencisine uygulanmış ve geribildirimleri alınmıştır. Bu uygulama sonucunda, öğrencilerin yarıdan fazlasının anlaşılır olmadığını düşündüğü maddeler bir alan uzmanı ve bir Türkçe Eğitimi alanında çalışan öğretim üyesinin yardımları doğrultusunda ölçek yeniden düzenlenmiştir.

GYDSBE Ölçeği'nin İngilizce formu ile Türkçe formu arasındaki tutarlığı belirlemek için dil geçerliği çalışması yapılmıştır. Bu çalışma İzmir ilindeki özel bir kolejde İngilizce seviyeleri iyi olan 87 altıncı sınıf öğrencisine, İngilizce ve Türkçe form dört hafta ara ile uygulanarak gerçekleştirilmiştir. Uygulama sonucunda elde edilen veriler ile Pearson momentler çarpım korelasyon katsayısı her bir senaryo için ayrı ayrı hesaplanmıştır. Tablo 1' deki sonuçlara göre, Türkçe ve İngilizce form uygulamaları arasındaki ilişki tüm senaryolar için anlamlı bulunmuştur $(\mathrm{p}<0.001)$. 
Tablo 1.

GYDSBE Ölçeği Senaryolarının Türkçe ve İngilizce Korelasyon Katsayıları

\begin{tabular}{cccc}
\hline Senaryo & $N$ & $r$ & $P$ \\
\hline Senaryo 1 & 87 & 0.68 & .000 \\
Senaryo 2 & 87 & 0.59 & .000 \\
Senaryo 3 & 87 & 0.61 & .000 \\
Senaryo 4 & 87 & 0.66 & .000 \\
\hline
\end{tabular}

Yapı geçerliği

GYDSBE Ölçeği'nin yapı geçerliği ve güvenirlik çalışması İzmir ilinde farklı ilçelerde bulunan üç devlet okulunda 6. sınıfta okuyan 175 kız ve 187 erkek, toplam 362 öğrenciden elde edilen veriler ile yapılmıştır. Yapı geçerliğini belirlemek amacıyla faktör analizi yapılmıştır. Faktör analizi sonucunda senaryolara göre ölçeğin KMO test değerleri 0.901 ile 0.968 arasında, Bartlett's test of sphericity değerleri ise tüm senaryolarda anlamlı $(\mathrm{p}<.001)$ bulunmuştur. Senaryolardaki maddelerin kaç faktörde toplandı̆̆ını belirlemek amacıyla öncelikle öz değerlere ve varyansın açıklama yüzdelerine bakılmıştır. Açımlayıcı faktör analizi sonuçları Tablo 2' de verilmiştir.

Tablo 2.

GYDSBE Ölçeği Maddelerinin Öz Değerleri ve Açıklanan Yüzdeleri

\begin{tabular}{lrrr}
\hline Senaryolar & Bileşenler & Özdeğer & \multicolumn{1}{c}{$\begin{array}{c}\text { Açılanan } \\
\text { varyans } \%\end{array}$} \\
\hline Senaryo 1 & 1 & 7,119 & 44,494 \\
\hline Senaryo 2 & 2 & 1,021 & 6,380 \\
\hline Senaryo 3 & 1 & 7,094 & 44,334 \\
\hline & 2 & 1,176 & 7,348 \\
\hline Senaryo 4 & 1 & 6,198 & 38,735 \\
\hline
\end{tabular}


Tablo 2 incelendiğinde senaryo 1 , senaryo 2 ve senaryo 3 'te iki bileşenin, senaryo 4'te bir bileşenin öz değerinin 1.00'ın üzerinde olduğu görülmektedir.

Tablo 3'te her maddenin faktör yükleri ve madde-test korelasyonları verilmiştir.

Tablo 3.

GYDSBE Ölçeği'ndeki Maddelerin Faktör Yükleri ile Madde-Test Korelasyonları

\begin{tabular}{|c|c|c|c|c|c|c|c|c|c|c|c|}
\hline & \multicolumn{3}{|c|}{ Senaryo 1} & \multicolumn{3}{|c|}{ Senaryo 2} & \multicolumn{3}{|c|}{ Senaryo 3} & \multicolumn{2}{|c|}{ Senaryo 4} \\
\hline $\begin{array}{l}\text { Maddel } \\
\text { er }\end{array}$ & $\begin{array}{l}\text { 1.Fakt } \\
\text { ör }\end{array}$ & $\begin{array}{l}\text { 2.Fakt } \\
\text { ör }\end{array}$ & $\begin{array}{l}\mathrm{r}(\mathrm{j} \\
\mathrm{x})\end{array}$ & $\begin{array}{l}\text { 1.Fakt } \\
\text { ör }\end{array}$ & $\begin{array}{l}\text { 2.Fakt } \\
\text { ör }\end{array}$ & $\begin{array}{l}\mathrm{r}(\mathrm{j} \\
\mathrm{x})\end{array}$ & $\begin{array}{l}\text { 1.Fakt } \\
\text { ör }\end{array}$ & $\begin{array}{l}\text { 2.Fakt } \\
\text { ör }\end{array}$ & $\begin{array}{l}\mathrm{r}(\mathrm{j} \\
\mathrm{x})\end{array}$ & $\begin{array}{l}\text { 1.Fakt } \\
\text { ör }\end{array}$ & $\begin{array}{l}\mathrm{r}(\mathrm{j} \\
\mathrm{x})\end{array}$ \\
\hline M1 & 692 &,- 157 & $\begin{array}{r}64 \\
1\end{array}$ & 675 &,- 192 & $\begin{array}{r}56 \\
8\end{array}$ & 607 & ,471 & $\begin{array}{r}56 \\
0\end{array}$ & 805 & $\begin{array}{r}, 78 \\
1\end{array}$ \\
\hline M2 & 618 &,- 200 & $\begin{array}{r}55 \\
7\end{array}$ & 674 &,- 222 & $\begin{array}{r}54 \\
4\end{array}$ & ,555 & ,522 & $\begin{array}{r}50 \\
7\end{array}$ & 805 & $\begin{array}{r}, 77 \\
5\end{array}$ \\
\hline M3 & ,714 &,- 407 & $\begin{array}{r}, 66 \\
1\end{array}$ & ,222 & 832 & $\begin{array}{r}18 \\
3\end{array}$ & ,713 & 427 & $\begin{array}{r}64 \\
9\end{array}$ & ,835 & $\begin{array}{r}80 \\
6\end{array}$ \\
\hline M4 & ,668 &,- 393 & $\begin{array}{r}, 60 \\
1\end{array}$ & ,721 & , 176 & $\begin{array}{r}, 66 \\
7\end{array}$ & ,686 & ,440 & $\begin{array}{r}, 62 \\
3\end{array}$ & 807 & $\begin{array}{r}, 77 \\
2\end{array}$ \\
\hline M5 & 665 &,- 247 & $\begin{array}{r}, 60 \\
6\end{array}$ & ,745 & , 000 & $\begin{array}{r}66 \\
7\end{array}$ & ,572 & ,399 & $\begin{array}{r}52 \\
2\end{array}$ & 845 & $\begin{array}{r}81 \\
7\end{array}$ \\
\hline M6 & ,708 &,- 147 & $\begin{array}{r}65 \\
2\end{array}$ & ,734 & ,205 & $\begin{array}{r}67 \\
5\end{array}$ & ,328 & ,409 & $\begin{array}{r}27 \\
4\end{array}$ & ,786 & $\begin{array}{r}75 \\
5\end{array}$ \\
\hline M7 & ,607 &,- 013 & $\begin{array}{r}, 55 \\
8\end{array}$ & ,710 & , 168 & $\begin{array}{r}, 63 \\
9\end{array}$ & ,466 &,- 246 & $\begin{array}{r}39 \\
5\end{array}$ & ,776 & $\begin{array}{r}74 \\
0\end{array}$ \\
\hline M8 & ,613 &,- 121 & $\begin{array}{r}, 55 \\
0\end{array}$ & 633 & ,069 & $\begin{array}{r}52 \\
8\end{array}$ & 637 &,- 113 & $\begin{array}{r}55 \\
9\end{array}$ & ,780 & $\begin{array}{r}74 \\
5\end{array}$ \\
\hline M9 & ,684 & , 021 & $\begin{array}{r}, 63 \\
2\end{array}$ & ,626 & ,323 & $\begin{array}{r}56 \\
8\end{array}$ & 671 &,- 246 & $\begin{array}{r}, 58 \\
6\end{array}$ & 800 & $\begin{array}{r}77 \\
0\end{array}$ \\
\hline M10 & ,652 & ,066 & $\begin{array}{r}, 59 \\
4\end{array}$ & ,715 & ,099 & $\begin{array}{r}, 62 \\
4\end{array}$ & ,618 &,- 363 & $\begin{array}{r}54 \\
4\end{array}$ & ,771 & $\begin{array}{r}73 \\
8\end{array}$ \\
\hline M11 & ,611 & ,449 & $\begin{array}{r}, 54 \\
7\end{array}$ & 678 &,- 175 & $\begin{array}{r}, 55 \\
8\end{array}$ & 690 &,- 386 & $\begin{array}{r}59 \\
4\end{array}$ & ,787 & $\begin{array}{r}75 \\
4\end{array}$ \\
\hline M12 & ,687 & ,234 & $\begin{array}{r}, 64 \\
2\end{array}$ & 661 &,- 263 & $\begin{array}{r}54 \\
2\end{array}$ & ,675 &,- 314 & $\begin{array}{r}, 59 \\
6\end{array}$ & ,782 & $\begin{array}{r}, 75 \\
4\end{array}$ \\
\hline M13 & ,714 & ,231 & $\begin{array}{r}66 \\
1\end{array}$ & ,724 &,- 170 & $\begin{array}{r}60 \\
4\end{array}$ & ,714 &,- 367 & $\begin{array}{r}62 \\
7\end{array}$ & 836 & $\begin{array}{r}80 \\
8\end{array}$ \\
\hline M14 & ,541 & ,395 & $\begin{array}{r}48 \\
4\end{array}$ & ,596 &,- 175 & $\begin{array}{r}47 \\
2\end{array}$ & ,604 &,- 287 & $\begin{array}{r}, 51 \\
4\end{array}$ & ,736 & $\begin{array}{r}69 \\
7\end{array}$ \\
\hline M15 & ,722 & ,211 & $\begin{array}{r}, 67 \\
2\end{array}$ & 661 &,- 132 & $\begin{array}{r}, 55 \\
3\end{array}$ & ,719 &,- 243 & $\begin{array}{r}64 \\
4\end{array}$ & ,835 & $\begin{array}{r}81 \\
8\end{array}$ \\
\hline M16 & ,742 & 152 & ,68 & $\begin{array}{l}708 \\
\end{array}$ &,- 016 & ,62 &, 572 & 212 &, 52 & ,819 & ,79 \\
\hline
\end{tabular}


Tablo 3 incelendiğinde, birinci faktörde her bir maddenin oldukça yüksek yükleri olduğu görülmektedir. Senaryo 2 'de 3 . maddenin ikinci faktördeki yükünün $0.10^{\prime}$ dan daha yüksek olmasına karşın; bu maddenin diğer senaryolarda birinci boyutta yüksek faktör yüküne sahip olduğu görülmektedir.

GYDSBE Ölçeği'nin ayırt ediciliğini belirlemek amacıyla her bir senaryodan alınan toplam puanlara göre oluşturulan alt \%27 ve üst \%27'lik grupların madde ortalama puanları arasındaki fark, ilişkisiz örneklemler için t testi kullanılarak karşılaştırılmıştır. En yüksek puanı alan ilk 97 kişi (\%27) üst gruba, en düşük puanı alan son 97 kişi (\%27) alt gruba dahil edilmiştir. Alt grup üst grup karşılaştırma sonuçları Tablo 4 'te verilmiştir.

Tablo 4.

GYDSBE Ölçeği Üst Grup- Alt Grup t Testi Sonuçları

\begin{tabular}{|c|c|c|c|c|c|c|}
\hline Senaryo & Grup & $N$ & $\bar{x}$ & $t$ & SS & $p$ \\
\hline \multirow{2}{*}{ Senaryo 1} & Üst Grup & 97 & 55,31 & \multirow{2}{*}{37,851} & \multirow{2}{*}{118,58} & \multirow{2}{*}{,000 } \\
\hline & Alt Grup & 97 & 21,04 & & & \\
\hline \multirow{2}{*}{ Senaryo 2} & Üst Grup & 97 & 46,77 & \multirow{2}{*}{20,221} & \multirow{2}{*}{97,856} & \multirow{2}{*}{,000 } \\
\hline & Alt Grup & 97 & 17,96 & & & \\
\hline \multirow{2}{*}{ Senaryo 3} & Üst Grup & 97 & 50,62 & \multirow{2}{*}{32,148} & \multirow{2}{*}{114,306} & \multirow{2}{*}{,000 } \\
\hline & Alt Grup & 97 & 20,94 & & & \\
\hline \multirow[b]{2}{*}{ Senaryo 4} & Üst Grup & 97 & 76,82 & \multirow[b]{2}{*}{61,592} & \multirow[b]{2}{*}{192} & \multirow[b]{2}{*}{,000 } \\
\hline & Alt Grup & 97 & 26,89 & & & \\
\hline
\end{tabular}


Tablo $4^{\prime}$ teki $\mathrm{t}$ testi sonuçlarının tüm senaryolar için anlamlı olduğu görülmektedir $(\mathrm{p}<.001)$. Bu sonuçlara göre, Ek 1'de verilen GYDSBE Ölçeği'nin tüm senaryolarının öğrencilerin bilişim teknolojilerinin etik kullanımını ölçmede ayırt edici olduğu söylenebilir.

\section{Güvenirlik}

GYDSBE Ölçeği' nin her senaryosu için ayrı ayrı Cronbach Alpha iç tutarlık katsayısı hesaplanmıştır. Cronbach Alpha Katsayısı senaryo 1 için 0.919, senaryo 2 için 0.815 , senaryo 3 için 0.884 ve senaryo 4 için 0.965 olarak bulunmuştur. Tablo 3 'teki bulgulara göre madde test korelasyon değerleri birinci senaryoda 0.484-0.688 arasında, ikinci senaryoda 0.183-0.675 arasında, üçüncü senaryoda $0.274-0.649$ arasında, dördüncü senaryoda 0.697-0.818 arasindadir.

\section{Sonuç ve Tartışma}

Bu çalışmada Yoon (2011) tarafından geliştirilen GYDSBE Ölçeği'nin Türkçeye uyarlama çalışması yapılmıştır. Bu kapsamda ölçeğin Türkçe çeviri çalışmaları İngilizce ve Türkçe alan uzmanlarınca yapılmış, bilişim teknolojileri alan uzmanlarının ve öğretmenlerinin görüşleri alınarak ön deneme uygulaması yapılmıştır. GYDSBE Ölçeği'nin dil geçerliği çalışması sonucunda İngilizce ve Türkçe formdaki tüm senaryolar arasındaki ilişkinin anlamlı ve orta düzeyde olduğu görülmüştür. GYDSBE Ölçeği'nin geçerlik çalışması için yapılan uygulamadan elde edilen verilerin açımlayıcı faktör analizine uygunluğunu belirlemek için KMO ve Barlett testi yapılmıştır. KMO katsayısı, veri matrisinin faktör analizi için uygun olup olmadığı ve veri yapısının faktör çıkarma için uygunluğu hakkında bilgi verir. Faktörleşebilirlik için $\mathrm{KMO}^{\prime}$ nun $.60^{\prime}$ tan yüksek çıkması beklenir. Barlett testi, değişkenler arasında ilişki olup olmadığını kısmi kolerasyonlar temelinde inceler (Büyüköztürk, 2009). KMO ve Barlett test değerleri veri setinin faktör analizi için uygun olduğunu göstermektedir. Faktör analizi sonucunda birinci bileşene ait özdeğerin ikinci bileşene ait öz değerden en az üç kat yüksek olması ve ikincisi ile daha sonrakiler arasında çok fazla bir farkın olmaması ölçeğin tek boyutlu olduğunu göstermektedir (Lord, 1980, Akt. Duyan ve Gelbal, 2008). Ölçeğin tek boyutlu olup olmadığına, birinci boyutta bulunan maddelerin faktör yüklerine bakarak da karar verilebilir. Birinci boyutta faktör yükü yeterince yüksek olan maddeler alınarak tek boyutlu bir ölçek elde etmek mümkün olabilir (Duyan ve Gelbal, 2008). Tablo 3 'te verilen madde faktör yükleri ölçeğin tek boyutlu olduğunun bir göstergesidir. Açımlayıcı faktör analizi sonucunda, senaryolarda toplam 
Gerçek Yaşam Durum Senaryolarıyla Bilişim Etiği Ölçeği'ni Türkçeye Uyarlama Çalışması 329 varyansın açıklanma yüzdesinin yüksekliği ve madde faktör yüklerinin yüksekliği nedeniyle, GYDSBE Ölçeği'nin ölçmek istediği yapıyı ölçebildiği ve tek boyutlu olduğu söylenebilir. Alt grup -üst grup karşılaştırmasında tüm senaryoların ayırt edici olduğu görülmüştür. Yapılan güvenirlik analizi sonucunda GYDSBE Ölçeği senaryolarının iç tutarlık katsayıları ölçeğin orijinalinin iç tutarlık katsayılarına benzer şekilde, 0.815-0.965 arasında bulunmuştur. Madde korelasyon katsayılarının, maddelerin ayırıcılığı için yeterli olması ve iç tutarlık katsayılarının yüksek olması nedeniyle GYDSBE Ölçeği'nin güvenilir olduğu söylenebilir. GYDSBE Ölçeği'nin bu yapısal özellikleri ile bilişim etiği araştırmalarında ve bilişim etiği öğretimi uygulamalarında kullanılabileceği düşünülmektedir. 
Kaynakça

Adam, A. \& Ofori-Amanfo, J. (2000). Does gender matter in computer ethics? Ethics and Information Technology, (2), 37-47.

Büyüköztürk, Ş. (2009). Sosyal bilimler için veri analizi el kitabı. Ankara:Pegem Akademi.

Bynum, T. (2000). The foundation of computer ethics. ACM SIGCAS Computers and Society, 30(2), 6-13.

Dedeoğlu, G. (2006). Etik ve bilişim. Ankara: Türkiye Bilişim Derneği Yayınları.

Dorantes, C. A., Hewitt, B. \& Goles, T. (2006). Ethical decision-making in an IT context: the roles of personal moral philosophies and moral intensity. Proceedings of the 39th Hawaii International Conference on System Sciences, 8, 206c. DOI:10.1109/HICSS.2006.161

Duyan, V. ve Gelbal, S. (2008). Barnett çocuk sevme ölçeği'ni Türkçeye uyarlama çalışması. Ĕ̆itim ve Bilim, 33(148), 40-48.

Floridi, L. (1995). Internet: which future for organized knowledge, Frankestein or Pygmalion?. International Journal of Human-Computer Studies, (43), 261-274.

Johnson, D. G. (2000). Computer ethics. New Jersey: Englewood Cliffs.

Lesk, M. (2005). Understanding digital libraries. Morgan-Kaufmann Publishers.

Loch, K. D. \& Conger, S. (1996). Evaluating ethical decision making and computer use. Communications of the ACM, 39(7), 74-83.

Mason, R. O. (1986). Four ethical issues of information age. MIS Quarterly,10(1), 5-11.

Masrom, M., Ismail, Z., Anuar, R. N, Hussein, R.\& Mohamed, N. (2010). Analyzing accuracy and accessibility in information and communication technology ethical scenario context. American Journal of Economics and Business Administration, 3(2), 370-376.

Moor, J. H. (1985). What is computer ethics?. Metaphilosophy, 16(4), 266-279.

OECD. (2011). Organisation for economic co-operation and development communication outlook. [http://www.oecd.org/sti/broadband/oecdcommunicationsoutlook2011.ht m\#data]. Erişim Tarihi: 27.01.2013.

Örs, F. (2010). Küresel medya ortamında yaşanan etik sorunlar ve uluslararası düzenlemeler. Journal of Yasar University, 20(5), 3443-3452.

Sevindik, T. (2011). Bilişim ve etik ders notları. [Çevrim-içi: http://www.yarbis.yildiz.edu.tr/web/userAnnouncementsFiles/dosya2f00 c8b17de373c9f729e1440b895329.pdfl, Erişim tarihi: 10.02.2013.

Shariff, S. (2005). Cyber-dilemmas in the new milennium: School obligations to provide students safety in a virtual school environment, Mc Gill Journal of Education, 40(3), 457-477. 
Gerçek Yaşam Durum Senaryolarıyla Bilişim Etiği Ölçeği'ni Türkçeye Uyarlama Çalışması 331

Siegler M. (2002). Training doctors for professionalism: some lessons from teaching clinical medical ethics. Mt Sinai J Med, (69), 404-9.

Türkiye Bilişim Derneği. (2010). Bilişim etiği nihai rapor.

[http://www.tbd.org.tr/usr_img/cd/kamubib14/raporlarPDF/RP22011.pdf]. Erişim tarihi: 07.07.2012.

Türk Patent Enstitüsü. (2012). Fikri mülkiyet ve küçük orta ölçekli işletmeler. [http://www.turkpatent.gov.tr/dosyalar/yayinlar/bilgikitapciklari/fikriml kytkobi.pdf]. Erişim tarihi: 20.12.2012.

Yoon, C. (2011). Ethical decision-making in the Internet context: Development and test of an initial model based on moral philosophy. Computers in Human Behavior, (27), 2401-2409. 
Ekler

\section{Ek 1. Gerçek Yaşam Durum Senaryolarıyla Bilişim Etiği Ölçeği}

Değerli Öğrenci,

Size sunulan bu ölçek, bilişim teknolojilerinin kullanımına ilişkin görüş ve tutumlarınızı belirlemeyi amaçlayarak oluşturulmuştur. Sizlerin görüş ve önerileri bu araştırmanın sonuçları bakımından büyük değer taşımaktadır.

Sizlerden istenilen, ölçme aracında yer alan senaryoları dikkatle okuyup, sorularda size en uygun gelen yanitı belirlemenizdir. Soruları sizin kendi görüşünüz doğrultusunda cevaplamanız önemlidir.

$\mathrm{Bu}$ ölçeğe vereceğiniz bilgiler sadece bilimsel amaçlı kullanılacak ve gizli tutulacaktır. Ölçeklerde ad-soyad gibi sizin kimliğinizi belli edecek herhangi bir bilgi koymayınız. Bu nedenle, lütfen sorulara gerçekçi yanıtlar veriniz ve bütün soruları yanıtlamaya özen gösteriniz.

Ölçeğe ayırdığınız zaman, gösterdiğiniz ilgi ve katkılarınız için çok teşekkür ederiz. 
Gerçek Yaşam Durum Senaryolarıyla Bilişim Etiği Ölçeği'ni Türkçeye Uyarlama Çalışması 333

Senaryo 1: Internette oyun oynamay1 seven Berna, bir gün ünlü bir oyun şirketinden e-posta alır. E-postaya göre; şirketin web sitesine üye olursa, şirketin çok sevilen ve tanınmış oyunlarından birini ücretsiz oynayabilecektir. Berna oyun oynamayı çok sevdiği için, siteyi ziyaret eder ve üye olur. Oyunu bir ay boyunca eğlenerek oynar. Bir ay sonra oyun şirketi Berna'ya başka bir eposta gönderir. Bu e-postada Berna'nın bir ay daha oyunu ücretsiz oynayabilmesi için teklifte bulunur. Teklifte, arkadaşlarının isim listesini ve eposta adreslerini şirkete göndermesi gerektiği belirtilmektedir.

Eylem: Berna, isimlerin ve e-posta adreslerin başkalarına verilmesinin yanlış olduğunu bilir. Ancak bedava oyun oynamayı çok istemektedir. Bu durumdan arkadaşlarının yararlanabileceğini de düşünür. Böylece listeyi şirkete vermiştir.

\begin{tabular}{|c|c|c|c|c|c|c|}
\hline & & 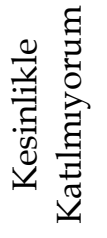 & 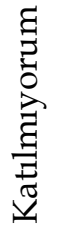 & $\begin{array}{l}\tilde{\Xi} \\
\text { స్ } \\
\text { పే } \\
\text { ప్ర }\end{array}$ & 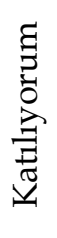 & 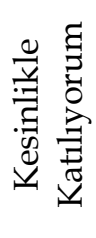 \\
\hline 1 & Berna'nın davranışı doğrudur. & & & & & \\
\hline 2 & Berna'nın davranışı adildir. & & & & & \\
\hline 3 & Berna'nın davranışı kültürel olarak kabul edilebilir. & & & & & \\
\hline 4 & Berna'nın davranışı geleneksel olarak kabul edilebilir. & & & & & \\
\hline 5 & Berna'nın davranışı ailem tarafından kabul edilebilir. & & & & & \\
\hline 6 & Berna'nın davranışı tedbirlidir. & & & & & \\
\hline 7 & Berna'nın davranışı fedakardır. & & & & & \\
\hline 8 & $\begin{array}{l}\text { Berna'nın davranışı zararı en aza indirirken, yararı en üst } \\
\text { düzeye çıkarır. }\end{array}$ & & & & & \\
\hline 9 & Berna'nın davranışı zarardan çok fayda getirmektedir. & & & & & \\
\hline 10 & Berna'nın davranışı memnuniyeti en üst düzeye çıkarır. & & & & & \\
\hline 11 & Berna'nın davranışı genel ahlak kurallarına aykırı değildir. & & & & & \\
\hline 12 & Berna'nın davranışı benim adalet anlayışıma aykırı değildir. & & & & & \\
\hline
\end{tabular}




\begin{tabular}{|l|l|l|l|l|l|l|}
\hline 13 & Berna'nın davranışı ahlaken doğrudur. & & & & & \\
\hline 14 & Berna'nın davranışı, dile getirilmemiş bir sözü ihlal etmez. & & & & & \\
\hline 15 & Berna'nın davranışı kabul edilebilir. & & & & & \\
\hline 16 & Berna'nın davranışı etiktir. & & & & & \\
\hline 17 & Ben de Berna'nın yaptığını yaparım. & & & & & \\
\hline
\end{tabular}

Senaryo 2: Cem ve Onur bir lisede öğrencidir. Onlar açık saçık, küfürlü şarkılar söyleyen ve gösterilerinde de bunları kullanan ünlü bir rock grubunun hayranlarıdır. Lisenin onlara verdiği internet alanını kullanarak, grubun faaliyetlerini arkadaşlarıyla paylaşmak üzere, grup için hayran web sayfası hazırlamışlardır. Onlar grubun müzik kliplerini, şarkı sözlerini, resimlerini ve çeşitli söyleşilerini bulup, hayran sayfasında yayınlamışlardır. Ancak, bir gün okul müdürü, Cem ve Onur' a yaptıkları sitede çok fazla açık saçık, küfürlü şarkı sözü ve resim bulunduğu için siteyi kapatmalarını söylemiştir.

Eylem: Cem ve Onur okul müdürünün isteğini geri çevirmiştir; çünkü müdürün bu isteği konuşma ve ifade özgürlüğüne aykırıdır.

\begin{tabular}{|c|c|c|c|c|c|c|}
\hline & & 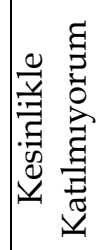 & 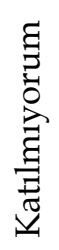 & 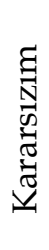 & 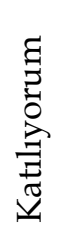 & 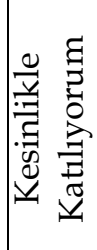 \\
\hline 1 & Cem ve Onur'un davranıșı doğrudur. & & & & & \\
\hline 2 & Cem ve Onur'un davranışı adildir. & & & & & \\
\hline 3 & $\begin{array}{l}\text { Cem ve Onur'un davranışı kültürel } \\
\text { olarak kabul edilebilir. }\end{array}$ & & & & & \\
\hline 4 & $\begin{array}{l}\text { Cem ve Onur'un davranışı geleneksel } \\
\text { olarak kabul edilebilir. }\end{array}$ & & & & & \\
\hline 5 & $\begin{array}{l}\text { Cem ve Onur'un davranışı ailem } \\
\text { tarafından kabul edilebilir. }\end{array}$ & & & & & \\
\hline 6 & Cem ve Onur'un davranışı tedbirlidir. & & & & & \\
\hline 7 & Cem ve Onur'un davranışı fedakardır. & & & & & \\
\hline 8 & Cem ve Onur'un davranışı zararı en aza & & & & & \\
\hline
\end{tabular}


Gerçek Yaşam Durum Senaryolarıyla Bilişim Etiği Ölçeği'ni Türkçeye Uyarlama Çalışması 335

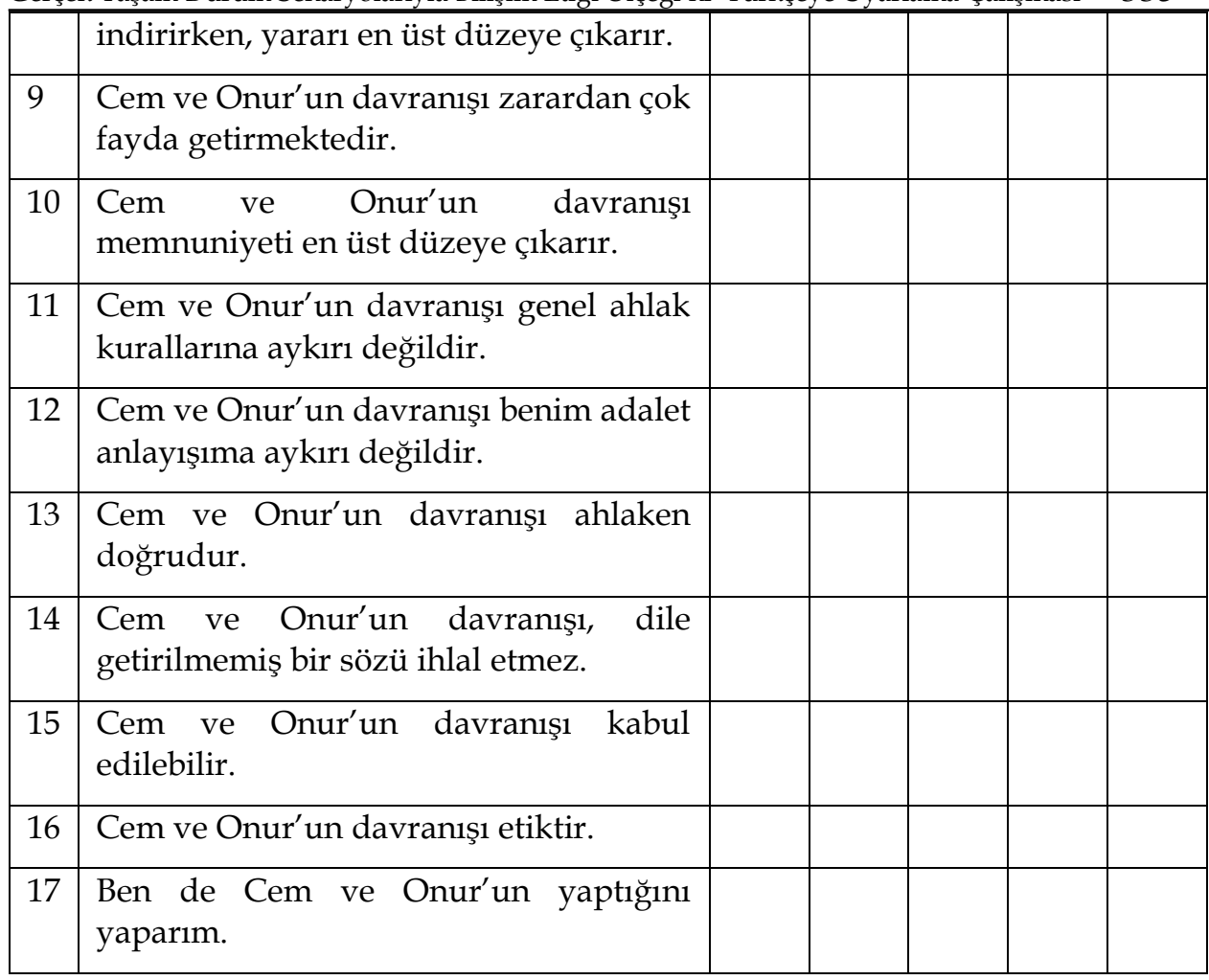

Senaryo 3: Bilgisayar yazılımlarıyla ünlü bir şirket, ürettiği yazılımlarını firmalar ve öğrenciler için farklı seçeneklerle sunmaktadır. Öğrenciler için olan yazılımının fiyatı $10 \mathrm{TL}$ 'dir. Şirket, yazılım üzerindeki haklarını korumak için, satın alma işleminden 3 gün önce öğrencilerle yasadışı çoğaltım yapmayacaklarına dair imzalı bir sözleşme yapar. Can sözleşme formunu doldurduktan sonra yazılımı satın alır. Bir gün Can'ın arkadaşı olan Berke, Can'a e-posta gönderir. E-postada kız arkadaşının dönem ödevi için acilen yazılıma ihtiyacı olduğunu fakat yasal yoldan yazılımı alamadığını söyler. Bu nedenle Berke, Can'dan yasal olmamasına rağmen kız arkadaşı için yazılımı kopyalamasını ister.

Eylem: Can, Berke'nin kız arkadaşının yazılıma acil ihtiyacı olduğunu düşünerek, yazılımı almadan önce bir sözleşme imzaladığını bilmesine rağmen, yazılımı kopyalamış ve Berke' ye vermiştir. 


\begin{tabular}{|c|c|c|c|c|c|c|}
\hline & & 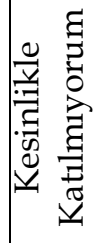 & 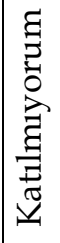 & 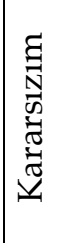 & 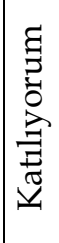 & 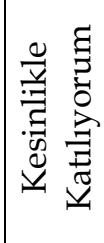 \\
\hline 1 & Can'ın davranışı doğrudur. & & & & & \\
\hline 2 & Can'ın davranışı adildir. & & & & & \\
\hline 3 & Can'ın davranışı kültürel olarak kabul edilebilir. & & & & & \\
\hline 4 & Can'ın davranışı geleneksel olarak kabul edilebilir. & & & & & \\
\hline 5 & Can'ın davranışı ailem tarafından kabul edilebilir. & & & & & \\
\hline 6 & Can'ın davranışı tedbirlidir. & & & & & \\
\hline 7 & Can'ın davranışı fedakardır. & & & & & \\
\hline 8 & $\begin{array}{l}\text { Can'ın davranışı zararı en aza indirirken, yararı en üst düzeye } \\
\text { çıarır. }\end{array}$ & & & & & \\
\hline 9 & Can'ın davranışı zarardan çok fayda getirmektedir. & & & & & \\
\hline 10 & Can'ın davranışı memnuniyeti en üst düzeye çıkarır. & & & & & \\
\hline 11 & Can'ın davranışı genel ahlak kurallarına aykırı değildir. & & & & & \\
\hline 12 & Can'ın davranışı benim adalet anlayışıma aykırı değildir. & & & & & \\
\hline 13 & Can'ın davranışı ahlaken doğrudur. & & & & & \\
\hline 14 & Can’ın davranışı, dile getirilmemiş bir sözü ihlal etmez. & & & & & \\
\hline 15 & Can’ın davranısıı kabul edilebilir. & & & & & \\
\hline 16 & Can'ın davranışı etiktir. & & & & & \\
\hline 17 & Ben de Can'ın yaptığını yaparım. & & & & & \\
\hline
\end{tabular}

Senaryo 4: Berçin bir üniversitede birinci sınıf öğrencisidir. Bir gün ünlü bir kozmetik şirketinden internet üzerinden ürünler alır ve bunları kullanır. Ama birkaç gün içinde cilt sorunları yaşamaya başlar. Berçin yaşadığı sorunları eposta ile şirkete bildirir ve parasının geri verilmesini ister. Ancak kozmetik şirketi, birçok müşterinin herhangi bir problemle karşılaşmadığını söyler ve isteği reddeder. Çoğu cilt sorununun bireyin kendisinden kaynaklandığını belirtir. 
Gerçek Yaşam Durum Senaryolarıyla Bilişim Etiği Ölçeği'ni Türkçeye Uyarlama Çalışması 337

Eylem: Berçin şirketin cevaplarını samimiyetsiz bulur ve ürünlerin kendisi gibi başkalarına da zarar verebileceğini düşünür. Bu nedenle internet üzerinden biraz abartılı, isimsiz ve herkesin okuyabileceği bir mesaj gönderir. Mesajda, üründe ciddi sorunlar olduğunu ve ürünü kullandıktan sonra kendisinin zarar gördüğünü belirtir.

\begin{tabular}{|c|c|c|c|c|c|c|}
\hline & & 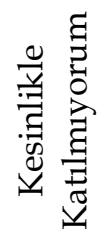 & 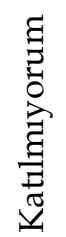 & 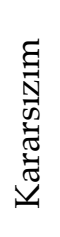 & 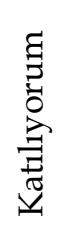 & 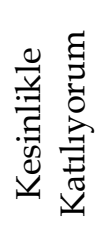 \\
\hline 1 & Berçin'in davranışı doğrudur. & & & & & \\
\hline 2 & Berçin'in davranışı adildir. & & & & & \\
\hline 3 & Berçin'in davranışı kültürel olarak kabul edilebilir. & & & & & \\
\hline 4 & Berçin' in davranışı geleneksel olarak kabul edilebilir. & & & & & \\
\hline 5 & Berçin'in davranışı ailem tarafından kabul edilebilir. & & & & & \\
\hline 6 & Berçin'in davranışı tedbirlidir. & & & & & \\
\hline 7 & Berçin'in davranışı fedakardır. & & & & & \\
\hline 8 & $\begin{array}{l}\text { Berçin' in davranışı zararı en aza indirirken, yararı en üst } \\
\text { düzeye çıkarır. }\end{array}$ & & & & & \\
\hline 9 & Berçin' in davranışı zarardan çok fayda getirmektedir. & & & & & \\
\hline 10 & Berçin' in davranışı memnuniyeti en üst düzeye çıkarır. & & & & & \\
\hline 11 & Berçin' in davranışı genel ahlak kurallarına aykırı değildir. & & & & & \\
\hline 12 & Berçin' in davranışı benim adalet anlayışıma aykırı değildir. & & & & & \\
\hline 13 & Berçin' in davranışı ahlaken doğrudur. & & & & & \\
\hline 14 & Berçin'in davranışı, dile getirilmemiş bir sözü ihlal etmez. & & & & & \\
\hline 15 & Berçin'in davranışı kabul edilebilir. & & & & & \\
\hline 16 & Berçin'in davranışı etiktir. & & & & & \\
\hline 17 & Ben de Berçin' in yaptığını yaparım. & & & & & \\
\hline
\end{tabular}

